Araştırma Makalesi •Research Article

\title{
Kadın Çalışanların Yaşam Kalite Algılarının Rol Stresi Üzerindeki Etkisi
}

\section{The Influence of Woman's Life Quality Perceptions on Role Stress}

\author{
Serdar Yener, ${ }^{a}$ Özgür Demirtaş, ${ }^{\text {** }}$ \\ ${ }^{a}$ Doç.Dr. Sinop Üniversitesi, Boyabat İİBF, Sinop/Türkiye. \\ ORCID: 0000-0002-6113-1528
}

${ }^{\text {b} D o c ̧ . D r ., K a y s e r i ~ U ̈ n i v e r s i t e s i, ~ S B F, ~ K a y s e r i / T u ̈ r k i y e . ~}$

ORCID: 0000-0002-2495-2124

\section{MAKALE BİLGİSI}

Makale Geçmişi:

Başvuru tarihi: 13 Eylül 2018

Düzeltme tarihi: 05 Ocak 2019

Kabul tarihi: 29 Ocak 2019

\section{Anahtar Kelimeler:}

Kadın Çalışanlar

Yaşam Kalite Algısı

Rol Çatışması

Rol Stresi

\section{A R T ICLE INFO}

Article history:

Received 13 September 2018

Received in revised form 05 January 2019

Accepted 09 January 2019

\section{Keywords:}

Woman Employee

Life Quality Perception

Role Stress

Role Conflict

\section{ÖZ}

Yaşam kalitesi algısı, bireylerin yaşamın birçok alanındaki ihtiyaçlarının karşılanma düzeyine göre memnuniyet ölçüsüdür. Bireylerin yaşamın farklı alanlarındaki ihtiyaçlarını karşılanmasının bireylerin yaşayacakları cinsiyet rol stresini azaltacağı düşünülmektedir. Birey ihtiyacı kuramı çerçevesinde kurulan modelin araştırılması içinSinop il ve ilçelerinde kamu ve özel sektörde ücretli çalıșan kadınlardan oluşan örneklem kullanılmıștır. Örneklemden toplanan veriler SPSS 21 ile analiz edilmiştir. Regresyon sonuçlarına göre kadınların yaşam kalite algılarının cinsiyet rol stresini olumsuz olarak etkilediği görülmüştür. Bu çalışma ile kadın çalışanlar ile (kamu-özel) yapılan anketler sonucu elde edilen verilerle, kadın rol stresinin kadınların yaşam kalite algıları üzerine olan etkisi ortaya konulmaya çalışılmıştır. Bu tarz saha çalışmalarının özellikle Türkçe literatür açısından henüz yeterince ele alınmamış olması mevcut çalışma ile sağlanabilecek potansiyel katkının önemini ortaya koymaktadır.

\section{A B S T R A C T}

Quality of life perception is determined by the satisfaction level of human needs in different areas of life. It is thought that female employee's quality of life perception decreases the level of feminine role stress. 212 Female employees working in government and private sectors of Sinop and its districts are consisting the sample group of the research. The research frame is based on human need theory. Data gathered from sample was analyzed with SPSS 21. According to the regression test results negative effect of quality of life perception on feminine role stress was observed. This study, which is taken to the consideration of the women who are working in public or private sector, is one of the rare researches that was being examined in Turkish literature.

\section{Giriș}

Kadınsı cinsiyet normlarının temeli toplum kültürü olup bir taraftan erkek egemen bir bakış açısı ve baskısını diğer taraftan toplumsal kültürün dayattığı örf, adet ve geleneklerin topluca yarattı̆̆ (Paluck ve Ball, 2010). Bu tarz bir önyargılı bakış açısı kadının iş dünyasındaki rekabet için zayıf kaldığı, kendini ișine veremediğini, kadınsı rolleri (hamilelik, annelik vs.) kullanarak kaytarma eğilimleri gösterdiği, ișinden bir anlam çıkaramadığından dolayı işini sevemediğini ve dolayısı ile

* Sorumlu yazar/Corresponding author

e-posta: demirtasozgur@yahoo.com düşük etkinlik ve verimlilik ile iş yaptığını savunabilmektedir (Paluck ve Ball, 2010).

Yaşam kalitesi ile anlatılmak istenen yaşamın bir çok alanındaki ihtiyaçların karşılanma düzeyi ve memnuniyet ölçüsüdür (Cummins vd., 2003; Haas, 1999). Bireylerin gereksinimleri, bu gereksinimlerin karşılanma düzeyi ve buna yönelik algıları arasındaki ilişki, değerlendirme kapasiteleri, kültürel bağlam, eğitimleri, bilgi düzeyleri, mizaç ve karakterlerinden kaynaklanan nedenlerden dolayı aynı toplumda aynı şartlara sahip bireylerde bile farklılık gösterebilmektedir (Constanza vd., 2007). Bu çerçevede en büyük öneme sahip faktör öznel boyut olup, bireylerin 
algılarının içinde yaşadığı kültürün değişkenlerine göre şekillendiği ifade edilmektedir (Azar, 2004). Herhangi bir topluma göre ihtiyaç olarak gösterilen bir faktörün bir başka toplumda ihtiyaç olarak görülmemesi, ihtiyaç karşılanma düzeyi problemini de ortadan kaldıracağı için memnuniyet düzeylerini etkileyebilir. İnsanların ihtiyaçları, kültürlerine bağlı olarak fiziksel barınma ve güvenlik ihtiyaçlarından başlayarak en üstte kendini gerçekleştirme vb. ihtiyaçlara kadar farklı şekilde ortaya çıktığı için, değerlendirmelerin de kültürel bağlamda yapılmasının gereklilik olduğu düşünülebilir. Kültür perspektifinden bakıldığında, farklı kültürlerde farklı nesnel göstergelere sahip bireylerin benzer yaşam kalitesi algısına sahip olması veya benzer nesnel göstergelere sahip bireylerin farklı yaşam kalitesi algılarına sahip olması (Schalock ve Keith, 2016) ihtiyaçlarının da kültüre göre şekillendiğini gösterebilmektedir.

Yapılan bu çalışma ile kadınların etkisinin gittikçe yoğun olarak hissedildiği günümüz iş yaşamında, kadının ev ve iş yerinde üstlenmiş olduğu farklı rollerin kadınlarda oluşturmuş olduğu stres üzerinde yaşam kalite algılarının etkisi ortaya konulmaya çalışılmıştır. Bireylerin yaşam kalite algısının bireylerin ihtiyaçlarına göre şekillendiği öngörüldüğünden bu araştırma Birey İhtiyacı Kuramı (Theory of Human Need, THN) çerçevesinde şekillendirilmiştir.

\subsection{Yaşam Kalitesi Algısı}

Yaşam kalitesi ile anlatılmak istenen yaşamın birçok alanındaki ihtiyaçların karşılanma düzeyi ve memnuniyet ölçüsüdür (Cummins vd., 2003; Haas, 1999; Duvdevany, 2010). Alanyazında bu konu ile ilgili yapılan çalışmalarda ortak noktanın, bireylerin kendi deneyimleri çerçevesinde geliştirdiği algı ile yaşam kalitesini değerlendirdiği şeklindedir (Constanza, 2007; Rzońca vd., 2018). Yaşam kalitesi göstergeleri olarak geçmişte ekonomik göstergeler referans alınmasına rağmen günümüzde bunun yeterli olmadığ 1 görülmektedir (Bognar, 2005). Geçmişte aynı toplumda yaşayan benzer ekonomik göstergelere sahip bireylerin benzer yaşam kalite algılarına sahip olacağ düşünülürken, günümüzde bireysel psikoloji ve alg1 süreçlerinin farklılığının yaşam kalitesi algılarını değiştirebildiği gözlemlenmektedir (Zapf, 2000). Bireylerin yaşam kalitesi algılarının sadece ekonomik göstergeler değil hayatın farklı alanlarındaki farklı rolleri veya durumlarıyla şekillenebildiği düşünüldüğünde, araştırma çerçevesinin öznel değişkenleri de içine alacak şekilde genişlemesi normal olarak görülmektedir. Bundan dolayı yaşam kalitesi araştırmalarında öznel göstergeleri ortaya koyan araştırma süreçleri yaygınlaşmaya başlamıştır. $\mathrm{Bu}$ yaklaşıma göre bireylerin öznel yaşam kalite algılarını ölçen herhangi bir yöntemin onların mutluluk veya yaşam memnuniyetlerini ölçebileceği önerilmektedir (Sumner, 1996). Bu yaklaşımda objektif göstergelerin (tanımlayıcı yaşam kalitesi göstergeleri) etkisinin en iyi öznel algılarla değerlendirilebileceği düşünülmektedir. İnsanların kendilerine yaşamı kolaylaştıran ürün, hizmet vb. araçlara sahip olmasının göstergesi olarak ifade edilen objektif göstergelerin (tanımlayıcı yaşam kalitesi göstergeleri) bireyler tarafından nasıl algılandığının ortaya konulması, yaşam kalitesi araştırmalarının temel amacı olmaktadır (Hagerty vd., 2001). Yaşam kalitesi araştırmalarının hem objektif hem subjektif göstergeleri içine alması, bir yandan da aynı objektif göstergelerin farklı kültürlerdeki etkisinin de ortaya konulması için önemlidir. Kültürlerarası karşılaştırmalar için referans olabilecek yaşam kalitesi araştırmaları devlet politikalarının da şekillendirilmesini sağlamaktadır (Rothstein ve Tannenberg, 2015). Öznel bakış açılarıyla salt bireylerin kendi deneyimlerini referans alan bir yaklaşımda bireylerin kendi deneyimlerini ne ölçüde tanımlayabildikleri bir başka problem sahasını oluştururken, nesnel bakış açılarıyla tüm insanoğlunun kalite algısını etkileyecek faktörlerin olduğunu önermekte hataya sürükleyebilir. Yaşam kalitesi bireyin fiziksel sağlığı, psikolojik durumu, otonomi derecesi, sosyal çevresi ve ilişkilerinden etkilenmektedir (Schalock vd., 2002). Bu değişkenler çerçevesinde içinde yaşadığı toplumda sosyal olarak bir çevreye sahip olup etkileşimde bulunan, yakın çevresinden destek ve saygı gören ve kendini güvende hisseden, kendini sözel veya farklı yollarla ifade edebilen, fiziksel olarak kendini sağlıklı hisseden bireylerin yaşam kalite seviyesinin yüksek olduğu söylenebilir. Buna göre yaşam kalitesi algısını şekillendiren etkenler (Pereira vd., 2006:14) aşağıdaki gibi sayılabilir;

- Psikolojik Durum: Bireyin yaşamdan doyum almasını, yararlı olduğunu düşünmesini, fiziki imaj algısını, gündelik hayatla ilgili uğraşlarına yönelik algısını şekillendiren psikolojik durum bireyin stres veya memnuniyet duymasını sağlar.

- Fiziksel Durum: Bireylerin gündelik yaşam aktivitilerini yerine getirebilme derecesini ifade etmektedir. Bunun seviyesi bireyin yaşam kalitesi algısını şekillendirmektedir.

- Sosyal Çevre ve Etkileşim: Bireyin yaşadığ1 sosyal çevrede çevresiyle etkileşim düzeyi ve bu sosyal çevrede kendini konumlandırması yaşam kalitesini şekillendirmektedir.

- Finansal Durumu: Bireyin yaşamı ve beklentisiyle orantılı olarak finansal durumu, ihtiyaçlarını ve beklentilerini karşılaması açısından yaşam kalite algısını şekillendirir.

Constanza vd. (2007) bireylerin ihtiyaçlarını karşılama konusunda sahip oldukları kaynakların, yaşam kalitesi algılarını şekillendirdiğini ifade etmektedir. Bu kaynaklar (s.271);

- Sosyal Sermaye: Bireyin sahip olduğu bağlantı ve ilişkilerini ifade etmektedir.

- İnsan Sermayesi: Bireysel sahip olunan bilgi ve düşünce yeteneğidir.

- Fiziksel Kaynaklar: Bireylerin gündelik gereksinimlerini yerine getirmede kullandıkları fiziksel araçlardır.

- Doğal Kaynaklar: Bireylerin yenilenebilir veya yenilemez kaynak ve hizmetlere sahip olma düzeyidir.

Yaşam kalite algısının bireylerin ihtiyaçlarına göre şekillendiği göz önüne alındığında, bu ihtiyaçları gidermek için sahip oldukları kaynakların da bu algının şekillenmesinde etkisi olduğu söylenebilir. Örneğin, barınma ve güvenlik ihtiyacının karşılanması için fiziksel kaynaklara; aidiyet ve sosyal katılım için de bireysel ilişki ve bağlantı kaynaklarına ihtiyaç duyulabilmektedir. Bu 
kaynaklardan fiziksel olanları, yani yenilenebiliryenilenemez kaynakların kullanım ömürlerininde gereksinimleri karşılama çerçevesinde yaşam kalitesi algısını etkilediği söylenebilir. Bireylerin yaşamın farklı alanlarındaki gereksinimlerine göre bilişsel ve duygusal deneyimleri şekillenmektedir (Sirgy, 2002). İhtiyaçların bireysel, toplumsal, ulusal ve evrensel değerlendirilmesi yaşam kalitesi algısının çok boyutlu olmasının bir başka nedenidir. Yaşamın farklı alanlarındaki ihtiyaçların bireylerin yaşam kalitesi algısını ne ölçüde etkilediği sorusunun cevabı ise ilgili alanın bireyin yaşamındaki önemidir. Bireyin, yaşamın herhangi bir alanına verdiği önem derecesi ve bu alandaki gereksinimlerinin karşılanma düzeyi, dolaylı olarak yaşam kalitesini de aynı derecede etkilemektedir. $\mathrm{Bu}$ önem derecesi topluma, zamana ve kültürel çevreye göre değişebilir (Constanza, vd., 2007). Schwarz ve Strack (1999) bireyin ilgili yaşam alanına verdiği önemi belirleyen birkaç faktörün olduğunu ifade etmektedirler. Bunlar ilgili yaşam alanının (s.65);

- Bireyin geçmişindeki pay1.

- Bireyin halihazırdaki yaşamındaki yeri.

- Bireyin geçmişindeki tanımı (Sıra dışı etki oluşturup oluşturmadiğg1).

- Diğerleriyle karşılaştırma konusunda referans derecesi ile

- Bireyin içinde yaşadığı toplumdaki diğer bireylerin ilgili yaşam alanına yönelik değerlendirmelerinden oluşmaktadır.

Bu açıdan bakıldığında yaşam alanlarının değerlendirilmesi daha değişken ve çok yönlü bir konu olmaktadır. Bireyin içinde bulunduğu toplum, kültür, zaman ve diğer değişkenlerin değişmesiyle birlikte bu alana verdiği önem de değişebilmektedir (Akdoğan ve Demirtaş, 2014). Örneğin, barınma ve güvenliğe yönelik ihtiyaçların zaman, toplum ve kültüre göre farklılaşacağı düşünülebilir. Dolayısıyla genel yaşam kalitesi algısının ölçülmesi sürecinde içinde, yaşanılan toplum, kültür, zaman vb. faktörlerin dikkate alınmasına ihtiyaç duyulmaktadır (Kagawa-Singer vd., 2010). Yaşam kalitesi algılarını şekillendiren ihtiyaçlar ve bu ihtiyaçların karşılanmasına aracılık eden kaynaklar yukarıda anlatılmıştı. Ancak ihtiyaç ve kaynaklarla yaşam kalitesi algısını etkilemesi açısından ele alınmasında önem atfedilen birkaç faktör daha bulunmaktadır. Bunlar (Constanza, 2007: 272);

- İhtiyaçların giderilmesiyle ihtiyaçların önemi arasındaki ilişki etki seviyesini şekillendirir. Yaşam kalitesi algısı için çok önemli görülen bir ihtiyacın giderilemeyecek derecede kaynağa ihtiyaç duyması veya yaşam kalitesi algısı açısından önemli olmayan bir ihtiyacın çok kolay giderilebilmesi.

- İhtiyacın giderilmesi ve ihtiyaç duyulan kaynağın sağlanması konusundaki uyumsuzluk,

- Nüfusun özelliklerinin farklılaşması,

- Toplumların herhangi bir ihtiyacının diğer toplum üzerinden karşılanması olarak sayılabilir.
$\mathrm{Bu}$ faktörler bireyleri, ihtiyaçları ve kaynakları konusunda yanlış değerlendirmelere itebilir. Örneğin Sirgy (2002), bireylerin deneyimleri, kendilerini kimliklendirmesi, beklentileri, sosyal anlamda diğerleriyle karşılaştırmaları gibi nedenlerle yanlış değerlendirmelere itilebileceklerini ifade etmektedir.

\subsection{Kadın Cinsiyet Rol Çatışması}

Biyolojik olarak kadın ve erkek cinsiyetine toplumun bakış açısı sahip olduğu değer algıları ve inanışlar yoluyla şekillenmektedir. Bu değer algıları ve inanışlar ise cinsiyete yönelik oluşturmuş olduğu normlarla toplumun kadın ve erkek bireylerinin alg1, tutum ve davranışlarını tanımlamaktadır. Kadın ve erkek bireyler toplumun değer ve inanışlarına göre oluşan normlarla kendilerine biçilen statü ve beklentiye göre davranırlar. Bireylerin kadınsı cinsiyet normlara göre şekillenen bu beklentiye uygun davranması, sosyal uyumu sağladığı için olumlu görülürken, uyumlu davranmaması sapma olarak ifade edilmektedir (Dudte, 2008). Bronfenbrenner (2005) sosyal normları bireylerin davranışlarının temel belirleyicisi olarak görmektedir.

Cinsiyet normları sosyal normların cinsiyete ilişkin türleridir (Eagly vd., 2004). Cinsiyet normları toplumda kadın ya da erkek cinsiyetine ilişkin yerleşmiş olan inanış ve tecrübelerden oluşmakta olup o toplum için beklenen davranışları belirler (Boudet vd., 2012). Cinsiyet doğal bir sınıflandırma olmasına rağmen kadın ve erkek sınıflandırması sosyal düşünce ve inanışlarla farklı şemalar oluşturarak kadın ve erkeğe ilişkin farklı senaryolarda farklı roller ortaya çıkarmıştır (Cialdini ve Trost, 1998). Burada hatırlanması gereken önemli bir konu, yukarıda ifade edildiği gibi kadınsı cinsiyet rollerinin kadının içinde yaşadığ senaryolara göre farklılaşabileceğidir. Çünkü roller, içinde yaşanılan toplumun genel inanışına ve tecrübelere göre şekillenen sosyal normlar tarafından belirlenmektedir. Cinsiyete ilişkin normların yayılması aile, öğretmen, akran ve arkadaşlar, medya gibi sosyal taşıyıcılar (Agents) tarafindan olmaktadır (Mahalik vd., 2005). Lytton ve Romney (1991) bireylerin beş yaşına geldiklerinde toplumda kadın ve erkeğe ilişkin rolleri tanımlayabildiklerini ifade etmektedir. Buradan toplumda kadın ve erkeğin davranışlarını yönlendiren cinsiyet normlarının bilindiğinden daha erken yerleştiği ve yerleşmesinden itibaren bireylerin davranışlarında etkiye sahip olduğu çıkarılabilir. Cinsiyet normları bireylerin doğumundan itibaren öncelikle ailelerin davranışlarıyla öğrenilmektedir. Ailelerin çocuklara cinsiyete göre farklılaşan davranışları, bakımı, kıyafet alması ve oyun oynaması, çocuğun etrafındaki kadın ve erkek cinsiyetlerin yaptıkları farklı işleri kadın ve erkek cinsiyetiyle ilişkilendirmesi, medya araçlarıyla tüketicileri etkilemek üzere cinsiyet farklılığı teması üzerindeki reklamlar bireylerin küçük yaşlardan itibaren cinsiyet konusunda şema oluşturmasını sağlar (Blackmore, 2003).

Cinsiyet normlarının kadın erkek eşitsizliğini desteklediği toplumlarda, kadın erkek eşitsizliklerinin cinsiyet normu olarak kabul edildiğini ifade etmek gerekir (Boudet vd., 2012). $\mathrm{Bu}$ toplumlarda kadınların erkeklerle karşılaştırıldığında hayatta daha fazla olumsuz sosyal normlara maruz kalması, sosyal normların toplumun 
genelindeki etkisinden dolayı normal olarak görülmekte olup, bu inanışların yakın zamanda da değişemeyeceği ileri sürülmektedir (Ridgeway, 1997). Bu durum neticesinde de kadınlarda işlerine karşı yılma veya tükenme durumları söz konusu olabilmektedir (Demirtaş, 2014).

Cinsiyet rol kuramı 1970'lerde SandraBEM'inalanyazına tanıttığı cinsiyet şema kuramına dayandırılmaktadır. Cinsiyet şema kuramı kişilerin cinsiyetlerine göre birtakım özellikler göstererek toplumsallaştığını önermektedir (Bem, 1981). Biyolojik cinsiyet insanların birbirine yönelik algılarını şekillendiren temel kategorilerden biridir. Biyolojik olarak cinsiyetler arasında birçok farklılığın olması, cinsiyete yönelik bir kategori oluşturmayı şart kılmıştır. Bu şekilde psikolojik şemalar oluşturularak insanların birbirine yönelik algıları şekillendirilmektedir. Kategorileştirme ile kast edilen cinsiyetin önceden öğrenilebilen ancak daha sonra toplumsal algılarla biraz daha şekillendirilebilen bir olgu olduğu varsayımıdır. Kadın ve erkeğin toplumda farklı rolleri ve görevleri olduğu düşünülmektedir. Toplum içerisinde bu şekilde bir kategorizasyon yapmak ve içselleştirmek için cinsiyet ve psikolojik cinsiyet ayrımını öneren iki tane kuram vardır. Bunlardan bir tanesi Cinsiyet diğeri de Benlik Şeması kuramıdır. Bem (1977) bu bağlamda cinsiyet rol ölçeğini cinsiyet şema kuramı ve cinsiyet rol kuramına göre oluşturmuştur. Cinsiyet rol ölçeğine göre 4 farklı cinsiyet rol yeterliliği önerilmektedir (Bem, 1977: 199). Bunlar;

- Cinsiyete bağlı şekillenen cinsiyet rolleri

- Diğer cinsiyete bağlı şekillenen roller

- Her iki cinsiyetten bağımsız şekillenen roller

- Her iki cinsiyete bağlı şekillenen roller.

O’Neil (2008) bireylerin cinsiyet rol çatışmasını, benlikleriyle uyuşmayan ve kendilerini kısıtlayarak zarar veren cinsiyet rolü yaşamaya zorlandıklarında yaşadıklarını ifade etmektedir. $\mathrm{Bu}$ ikilem ile görev ve sorumluluklar zamanla strese yol açmakta ve kişi zarar görebilmektedir (Greenhaus ve Beutell, 1985). Bir yandan toplumun beklentilerini ve dayatmalarını yerine getirmeye çalışmakta, diğer yandan sahip olduğu potansiyelin ortaya çıkarılması engellendiğinden eli kolu bağlı hissetmekte ve maruz kaldığı psikolojik rahatsızlık ile öngörülemeyen zararlar görebilmektedir (Stillson vd. 1991). Örneğin, erkek rollerini yaşamak zorunda kalmak, öz bakım yetersizliği, içselleştirme ve duyguların bastırılması, hesapsız risk alma davranışlarını doğurmaktadır (Liu vd., 2005). Benzer şekilde araştırmalarda kadınsı rollerini yaşamak zorunda kalan bireylerin, diğerlerine kendinden daha fazla öncelik vermesi ile dolaylı bir mutsuzluk yaşamasına neden olmaktadır (Richmond vd., 2015).

O’Neil ve Denke (2016) Cinsiyet rol çatışmasının aşağıda ifade edilen farklı psikolojik içeriklerde yaşandığını belirtmektedir. Bunlar (O’Neil ve Denke, 2016:54);

- Cinsiyet rolleri hakkındaki bilişsel düşünce,

- Baskın cinsiyet rolüne göre davranırken diğer rollerin bastırılması,

- Cinsiyete dayalı rolleri gösterirken başarı ya da başarısızlık durumunda yaşanılan mutluluk ya da keder,
- Bilinçli olarak ifade edilmeyen duygu, düşünce ve davranışlar.

Erkek cinsiyet rol çatışması konusunda çeşitli çalışmalar yapılmış olmasına rağmen kadın rol çatışmasına ilişkin kapsamlı herhangi bir kuram ortaya konulamamıştır. Kadın rol çatışmasına ilişkin Coyle vd. (2015:9) tespitleri aşağıda yer almaktadır;

- Bazı kadınların bedenlerinin erkeksi yaratılışından dolayı maruz kaldıkları çatışma,

- Yaşamlarındaki amaçsızlık (unassertiveness),

- Erkeklere karşı saygı ve itaat dayatması,

- Annelik, aile ve ev işlerinin kendilerinden ve kariyerlerinden öncelik kazanması gibi konular çözüm bekleyen sorular.

Yüksek cinsiyet rol çatışmasına sahip bireylerin daha fazla stres yaşadıkları ifade edilmektedir (Liu vd., 2005; MAtud, 2004). Levant vd. (2007) cinsiyet rollerinin ve cinsiyet rol stresinin cinsiyetin yanında kültürden de kaynaklanabildiğini söylemektedir. Örneğin, erkekler açısından cinsiyet rol çatışması bazen bir tartışmada odak noktası olduklarında ya da erkekliklerine karşı bir tehlike sezdiklerinde ortaya çıkabilmektedir (Mahalik vd., 1998). Erkekler bu tür savunma mekanizmasına dayalı tepkisel rol çatışmasını, güven ve üstünlük ile ilgili erkeklik normlarında yaşadıkları çelişkilerde gösterebilmektedir. Ve ayrıca rol çatışması yüksek olan erkeklerin şiddet, diğerlerine baskınlık kurma ve kullanma gibi davranışlar sergiledikleri de iddia edilmektedir (Amato, 2012). Diğer yandan kadın rol stresi, düşük özsaygı ve özgüven, depresyon, düzensiz yeme alışkanlığı, utangaçlık ve endişe gibi nedenlerden kaynaklanabilmektedir (Efthim vd., 2001).

Kadın cinsiyet rol stres ölçeği ise Gillespie ve Eisler tarafindan (1992) alan yazına kazandırılmış olup beş alt faktörden oluşmaktadır. Bunlar (s.430);

- Duygusal olmayan ilişki korkusu.

- Fiziksel çekici olmama.

- Kurban olma (victimized, obje olma).

- İddialı davranış.

- Destek ihtiyacı şeklindedir.

\subsection{Yaşam Kalite Algısı ve Kadın Rol Stresi İlişkisinin Kuramsal Altyapısı}

Kadının rolü geleneksel toplumlarda ev çevresinde şekillendiği için işteki rolleri de bazen ikinci planda kalabilmekte ve öncelik hep ev olacağından işe yönelik olumsuz algılar ortaya çıkabilmektedir. Çalışan kadın sayısının artması ve şehirleşme ile birlikte olumsuz tavırlarda göreceli bir azalışın olduğu görülse de kadının evde veya işte ihtiyaç duyacağı yardım ve desteği sağlama konusunda sorunlar halen yaşanmaya devam etmektedir. Ev ve işteki olumsuz duygular, memnuniyetinin düşmesine ve mutsuz olmasına yani yaşam kalite algısının düşmesine yol açabilmektedir. Buradan hareketle, yüksek yaşam kalitesi algısının, kadınsı cinsiyet normları ve cinsiyet rol stresi arasında düzenleyici rol oynayabileceği ve olumsuz etkinin düzeyini düşürebileceği düşünülmektedir. Buna göre bir toplumda yaşayan bireylerin hangi rolü oynayacakları konusu büyük ölçüde o topluma ait normlar tarafindan belirlenmekte (Bem, 1981) ve bu kültürden kültüre farklılık 
gösterebilmektedir (Dökmen, 2004). Günlük iş yaşamında kadın çalışan yüksek performans beklentisi ile erkeklerle sıkı bir şekilde rekabet etmeye çalışmaktadır. Aynı zamanda evde şefkatli ve çocuklarının üzerine titreyen bir anne ama aynı zamanda eşinin arzu ve isteklerini duraksamadan yerine getirmeye çalışan bir kadın ve nihayet ev işlerini titizlikle yapan ve herkesin arkasını toparlamaya çabalayan bir hizmetçi olmaya gayret etmektedir. Bu tarz farklı yerlerde farklı rollere bürünmek zaman zaman birbiriyle çakışan rollerin oluşmasına neden olabilmektedir. Aslında kadına biçilen rol daha önceki bölümlerde bahsedilen şemalar yoluyla zihnimizde oluşan ve farklı senaryolardaki deneyimlerimize göre şekillenen rollerini oynamaktadırlar. Aynı şey erkekler için de söylenebilir.

Kadınların farklı alanlardaki rolleri, baş edebilecek kaynaklarının yetersizliğinden dolayı (Repetti, 1987), oluşabilecek rol stresini sürekli hale getirebilir. Bu durumda fiziki ve ruhsal olarak tepki verecek gücü de kalmamakta tükenmişlik yaşayabilmektedir (Hayes ve Mahalik, 2000).

Birey İhtiyacı Kuramına (Theory of Human Need, THN) göre bütün toplumlarda kişisel ihtiyaçların temeli otonomi ve sağlıktır ve bunların sağlandığı sürece insanların yaşam memnuniyeti duydukları ifade edilmektedir (Doyal ve Gough, 1991). Bundan yola çıkarak bireyin ulaşılabilir, kendini zorlayan, yeteneklerini ortaya çıkaran ve diğerlerinden farklılaştıran amaçlarına ulaşma sürecinin otonomi sağlayacağını ve bu otonomi seviyesinin yaşam memnuniyetinin göstergesi olabileceği ifade edilmektedir (Ryan ve Deci, 2000). Bireysel toplumlarda yaşam memnuniyeti duygusuyla yüksek anlamlılık gösteren otonomi seviyesi, kollektivist toplumlarda aynı etkiyi göstermemektedir (Oishi ve Diener, 2001). Ulusal gelişmişlik seviyesi ve gelirin yaşam memnuniyeti üzerinde bireysel gelirden daha fazla etkiye sahip olduğu ifade edilirken, bireylerin algılarını toplumdaki diğer bireylerin de etkilediği ifade edilmektedir. Diener ve Suh ( 2000) bunu kültüre bağlayarak fiziksel olarak olumsuz şartlara sahip bütün toplumlarda öznel iyi oluş seviyesinin düşük olmadığını ifade etmektedir. Genel olarak ulusal gelirin artmasıyla birlikte altyapı ve diğer fiziksel imkanların seviyesinin artarak toplumun genelinin olumlu duygularını arttıracağı düşünülebilir.

Birey ihtiyacı kuramından yola çıarak kadınların yaşamlarının farklı alanlarındaki rollerinin ortaya çıkaracağı rol stresinin yaşamın farklı alanlarındaki ihtiyaçlarının giderilmesiyle düşebileceği düşünülmektedir. Bu çerçevede aşağıdaki hipotez oluşturulmuştur.

Hipotez: Algılanan yaşam kalitesi kadınsı normların yaratabileceği cinsiyet rol stresini azaltır.

\section{Yöntem}

Çalışmanın yöntem kısmına yönelik yapılan değerlendirmeler aşağıdaki başlıklar halinde sunulmuştur.
Sinop il merkezi ve ilçelerinde kadın çalışanların yaşam kalite algılarının cinsiyet rol stresi üzerine etkisinin araştırılması hedeflenmiştir. Kısaca, erkek egemen bakış açısı ve toplumsal dayatmaların sonucu oluşan kadın rol stresinin kadınların yaşam kalite algılarından ne ölçüde etkilendiği araştırılmıştır.

\subsection{Yöntem}

Sinop il merkezi ve ilçelerinde çalışan yaklaşık 400 çalışan kadın kolayda örnekleme yoluyla tespit edilmiş olup yüz yüze görüşmeler ile veya zamanı olmayan çalışanlardan daha sonra alınmak suretiyle formlar toparlanmış olup, nihai değerlendirmede analize tabi tutulan örneklem sayısı 212 olarak gerçekleşmiştir. Bu kadınların \%61'i kamu olmak üzere kalan \%39'luk kesim de Özel Sektör adı altında çalışmalarına devam etmektedirler. Kadınların \%57.5'i lisans seviyesi eğitime sahip olup, genelde 26-33 yaş aralığı olarak tespit edilen orta yaş grubuna yakın bir örneklem söz konusudur.

Çalışma kapsamında toplanan veriler IBM SPSS 21 programı ile analiz edilmiştir.

\subsection{Konu Kapsamı}

Sinop İl Merkezi ve ilçelerinde 212 kadın çalışanla (kamuözel) yapılan anketler sonucu elde edilecek verilerle, kadın rol stresinin kadınların yaşam kalite algıları üzerine olan etkisi ortaya konulmaya çalışılmıştır. $\mathrm{Bu}$ ve benzerialan çalışmalarının yeterli düzeyde olmadığı değerlendirildiğinden, mevcut çalışma ile Türkiye genelinde kadın çalışmalarına 1 şı tutacak nitelikte bir çalışmanın gerçekleştirilmesi ve ilgili alanyazına katkı sağlanması amaçlanmaktadır.

\section{4. Ölçekler}

Çalışmada kullanılan ölçekler aşağıdaki gibidir.

\subsubsection{Yaşam Kalitesi Ölçeği}

Orijinali SF36 olarak bilinen ve ilk olarak Ware ve Sherbourne (1992) tarafindan alan yazına kazandırılan bu ölçeğin Türkçe'deki karşılığı MF07-01 "Yaşam Kalitesi Formu" olarak bilinmektedir. Bu kapsamda toplamda 17 soru sorulmuştur.

\subsubsection{Kadın Rol Stresi Ölçeği}

Gillespieve Eisler (1992) tarafinda alan yazına kazandırılan ölçek Türkçe'de bulunamadığından bu proje kapsamında pilot uyarlaması da yapılmıştır. Toplam 39 sorudan oluşmaktadır.

\subsection{Tanımlayıcı İstatistiksel Sonuçlar}

Örnekleme ait tanımlayıcı bilgiler (medeni durum, yaş, konum, eğitim seviyesi) aşağıdaki Çapraz Tablo 1 ve Tablo 2 'de verilmiştir. 
Tablo 1. Medeni Durum ve Yaşı Gösterir Tablo

\begin{tabular}{lllll}
\hline & & Medeni Durum & & Toplam \\
\cline { 2 - 4 } & & Evli & Bekar & 12 \\
\hline \multirow{2}{*}{ Yaşınız } & 2 & 10 & 105 \\
\cline { 2 - 5 } & $18-25$ & & 73 & 95 \\
\hline Toplam & $26-33$ & 32 & 73 & 212 \\
\hline
\end{tabular}

Tablo 2. Eğitim Durumu ve Çalışma Konumunu Gösterir Tablo

\begin{tabular}{lllll}
\hline & & İşyerindeki Konumunuz & \multicolumn{2}{c}{ Toplam } \\
\cline { 2 - 5 } & & Yönetici-Yön. Yrd. & Düz Çalışan & \\
\hline \multirow{3}{*}{$\begin{array}{l}\text { Eğitim } \\
\text { Durumunuz }\end{array}$} & Lise-MYO & 7 & 65 & 72 \\
\cline { 2 - 5 } & Lisans & 2 & 122 & 124 \\
\cline { 2 - 5 } & Yüksek Lisans-Master & 9 & 4 & 13 \\
\cline { 2 - 5 } Toplam & Doktora & 3 & 0 & 3 \\
\hline
\end{tabular}

\subsubsection{Analiz Sonuçları}

Çalışmanın analiz sonuçları şu şekilde özetlenebilir.

2.5.1.1. Değişkenlere ait Güvenirlik ve Geçerlik Analiz Sonuçları

Modelde yer alan her değişkene ait geçerlik analizi için KMO değerlerine, faktör yüklerine ve teklik değerlerine bakılmıştır. \%30'dan az olan faktör yüküne sahip ifadeler çıkartılmıştır. Güvenirlik analizleri için de hem alt faktörler hem de her ölçeğin genel güvenirlik değeri olan alpha katsayıları incelenmiştir.
Kadın Rol Stresi Ölçeği Değişkenlerine ait Güvenirlik ve Geçerlik Analizleri

Kadın Rol Stresi ölçeğine aitanaliz sonuçları aşağıda sunulmuştur. \%30'dan düşük faktör yüküne sahip toplam 6 ifade çıkarılarak analizler yapılmıştır. Sonuçlara göre ölçek KMO değeri yeterlidir (\%96). Ölçek iki faktörden oluşmakta olup tüm ölçeğin güvenirlik katsayısı \%95'dir. Sonuçlara ait detaylı analizler aşağıdadır. Faktör yükleri düşük olan $16,19,24,25,36,37$ no'lu ifadeler çıkarılmıştır.

Tablo sonuçlarındaki Ki Kare değereri ve anlamlılıklarından da anlaşılacağı üzere ölçeğin iki faktörden ibaret olduğu sonucu anlamlı olarak değerlendirilmiş ve analizlere geçilmiştir.

Tablo 3. Kadın Rol Stresi Ölçeğine ait Faktör Analizi Sonuçları

\begin{tabular}{|c|c|c|c|}
\hline $\mathrm{KMO}=$ & & & \\
\hline Rotsdy & nalvarim & er on) & \\
\hline & Factor1 & Factor2 & Uniqueness \\
\hline Rol1 & 0,54 & & 0,64 \\
\hline Rol2 & 0,54 & & 0,62 \\
\hline Rol3 & 0,55 & & 0,62 \\
\hline Rol4 & 0,52 & & 0,66 \\
\hline Rol5 & 0,57 & & 0,59 \\
\hline Rol6 & 0,52 & & 0,62 \\
\hline Rol7 & 0,60 & & 0,60 \\
\hline Rol8 & 0,63 & & 0,55 \\
\hline Rol9 & 0,60 & & 0,61 \\
\hline Rol10 & 0,60 & & 0,62 \\
\hline Rol11 & 0,55 & & 0,63 \\
\hline Rol12 & 0,51 & & 0,67 \\
\hline Rol13 & 0,56 & & 0,61 \\
\hline Rol14 & 0,48 & & 0,68 \\
\hline Rol15 & 0,56 & & 0,62 \\
\hline Rol17 & 0,58 & & 0,57 \\
\hline
\end{tabular}




\begin{tabular}{|c|c|c|c|c|}
\hline Rol18 & 0,50 & & 0,66 & \\
\hline Rol20 & 0,60 & & 0,59 & \\
\hline Rol21 & 0,50 & & 0,65 & \\
\hline Rol22 & 0,50 & & 0,63 & \\
\hline Rol23 & 0,55 & & 0,57 & \\
\hline Rol26 & & 0,52 & 0,58 & \\
\hline Rol27 & & 0,53 & 0,54 & \\
\hline Rol28 & & 0,55 & 0,53 & \\
\hline Rol29 & & 0,62 & 0,58 & \\
\hline Rol30 & & 0,63 & 0,54 & \\
\hline Rol31 & & 0,63 & 0,50 & \\
\hline Rol32 & & 0,62 & 0,56 & \\
\hline Rol33 & & 0,61 & 0,51 & \\
\hline Rol34 & & 0,67 & 0,49 & \\
\hline Rol35 & & 0,57 & 0,57 & \\
\hline Rol38 & & 0,57 & 0,62 & \\
\hline \multirow[t]{2}{*}{ Rol39 } & & 0,61 & 0,57 & \\
\hline & & Tüm ölçek & $\alpha=0,95$ & \\
\hline Faktör & Varyans & Fark & Oran & Kümülatif \\
\hline Faktör 1 & 7,56 & 1,73 & 0,50 & 0,50 \\
\hline Faktör 2 & 5,83 & & 0,39 & 0,89 \\
\hline
\end{tabular}

Yaşam Kalitesi Ölçeği Değişkenlerine ait Güvenirlik ve Geçerlik Analizleri

Yaşam kalitesi ölçeğine aitanaliz sonuçları aşağıda sunulmuştur. \%30'dan düşük faktör yüküne sahip toplam tek ifade çıkarılarak analizler yapılmıştır. Sonuçlara göre ölçek KMO değeri yeterlidir (\%85). Bu ölçek de üç faktörden oluşmakta olup tüm ölçeğin güvenirlik katsayısı \%76'dır.
Ölçek için faktör analizi genellikle yapılmamakta ve her 8 faktör için bir puan hesaplaması olmaktadır (Bkz. http://www.ftronline.com/sf-36-nasil-hesaplanir/). Araştırma modeli için kullanılan 16 maddenin aritmetik ortalamasını alınarak analizlere dahil edilmiştir. Akademik çalışma olması nedeniyle diğer değişkenlerde olduğu gibi bu değişken için de faktör analizi yapılmıştır. Sonuçlara ait detaylı analizler aşağıda sunulmuştur.

Tablo 4. Yaşam Kalitesi Ölçeğine ait Faktör Analizi Sonuçları

\begin{tabular}{|c|c|c|c|c|}
\hline \multicolumn{5}{|c|}{$\mathrm{KMO}=0,85$} \\
\hline \multicolumn{5}{|c|}{ Rotasyon: obliquepromax (Kaiser on) } \\
\hline Variable & Factor1 & Factor2 & Factor3 & Uniqueness \\
\hline YasKal1 & 0,36 & & & 0,78 \\
\hline YasKal2 & 0,36 & & & 0,79 \\
\hline YasKal3 & 0,44 & & & 0,77 \\
\hline YasKal4 & & 0,35 & & 0,85 \\
\hline YasKal5 & & 0,42 & & 0,79 \\
\hline YasKal7 & & 0,51 & & 0,74 \\
\hline YasKal8 & & 0,30 & & 0,84 \\
\hline YasKal9 & & 0,35 & & 0,75 \\
\hline YasKal10 & & & 0,35 & 0,78 \\
\hline YasKal11 & & & 0,47 & 0,67 \\
\hline YasKal12 & & & 0,35 & 0,77 \\
\hline YasKal13 & & & 0,39 & 0,75 \\
\hline YasKal14 & & & 0,51 & 0,76 \\
\hline
\end{tabular}




\begin{tabular}{|c|c|c|c|c|}
\hline YasKal15 & & & 0,40 & 0,81 \\
\hline YasKal16 & & & 0,51 & 0,77 \\
\hline \multirow[t]{2}{*}{ YasKal17 } & & & 0,32 & 0,89 \\
\hline & & & Tüm ölçek & $\alpha=0,76$ \\
\hline Faktör & Varyans & Oran & & \\
\hline Faktör 1 & 2,32 & 0,83 & & \\
\hline Faktör 2 & 2,06 & 0,74 & & \\
\hline Faktör 3 & 1,37 & 0,49 & & \\
\hline \multicolumn{5}{|c|}{ LR test: independentvs, saturated: $\operatorname{chi} 2(120)=802,55$ Prob $>$ chi $2=0,0000$} \\
\hline
\end{tabular}

2.5.1.2. Araştırma Modeli için Yapılan Analiz Sonuçları

Araştırma modelinde ileri sürülen ilişkilerin analizi için bir istatistik programı kullanılmıştır. Analize tabii 212 kişilik örneklem büyüklüğü \%95 güven aralığında bootstrap yöntemi ile 5000 olarak yeniden oluşturulmuştur. Bootstrap yöntemi ile analize giren veri setinden daha büyük veri setleri üretmek amaciyla yeniden örnekleme yapabilme mümkün olabilmektedir (Sacchi, 1998). Böylece küçük veri setlerinde çıkan sonuçların sağlıklı olup olmadığını kontrol etmek için, yeniden örnekleme ile elde edilen daha büyük veri setleri için de benzer analizler yapılmakta ve benzer sonuçlar verip vermediğine bakılmaktadır. Ayrıca normal dağılım vb. önşartlar gerektirmediği de ileri sürülmektedir (Hayes, 2013).
Regresyon analizlerinden önce modelde yer alan değişkenler arası bir ilişkinin olup olmadığına da bakılmış ve bu amaçla yapılan pearsonkorelasyon testi sonuçları Tablo 5'de $(R=-$, 531) verilmiştir.

Yaşam kalitesinin kadın rol stresi üzerinde etkili olduğu e bu etkinin de istatistiksel olarak anlamlı olduğu anlaşılmaktadır $\left(\beta=-0,38, \mathrm{p}<, 000 ; \% 95 R^{2}=, 28\right)$. Bu sonuçlara göre algılanan yaşam kalitesinin kadınların yaşayacağı cinsiyet rol stresini \% 38 azaltabileceği ve cinsiyet rol stresinin \% 28 'nin yaşam kalitesine bağlı olduğu düşünülmektedir.

Tablo 5. Değişkenler Arasındaki Korelasyon Test Sonucu

\begin{tabular}{llll}
\hline & & RolStres & YasKalite \\
\hline \multirow{2}{*}{ RolStres } & PearsonCorrelation & 1 &,$- 531^{* *}$ \\
\cline { 2 - 3 } & Sig. (2-tailed) &, 000 \\
\hline \multirow{2}{*}{ YasKalite } & PearsonCorrelation &,$- 531^{* *}$ & 1 \\
\cline { 2 - 3 } & Sig. (2-tailed) &, 000 & \\
\cline { 2 - 3 } & & & \\
\hline
\end{tabular}

Tablo 6. Araştırma Model Özeti

\begin{tabular}{lllll}
\hline Model & $\mathrm{R}$ & $\mathrm{R}$ kare & Düzenlenmiş R kare & Std. Hata \\
\hline 1 &, $531^{\mathrm{a}}$ &, 282 &, 279 &, 50381 \\
\hline
\end{tabular}

a. Bağımsız Değişken: Rol Stres

\begin{tabular}{|c|c|c|c|c|}
\hline \multicolumn{5}{|c|}{ Katsayılar $^{\mathbf{a}}$} \\
\hline \multirow[t]{3}{*}{ Model } & Stand & & EdilmemişStandardize & \multirow[t]{3}{*}{ Anlamlilik. } \\
\hline & Katsay & & Katsayılar & \\
\hline & $\mathrm{B}$ & Std. Hata & Beta & \\
\hline (Sabit) & 3,595 & ,108 & & $33,374,000$ \\
\hline \multicolumn{2}{|c|}{ RolStres-,388 } & ,043 &,- 531 & $-9,083,000$ \\
\hline
\end{tabular}

a. Bağımlı Değişken: YasKalite 


\section{Sonuç ve Öneriler}

\subsection{Sonuç}

Modelde yaşam kalitesinin normların baskısı sonucu kadınların yaşayabileceği kadın cinsiyet rol stresini azaltabileceği görülmüştür. Yapılan analizler sonucu bu savların doğrulandığı görülmüştür. Yaşam kalitesi algısını olumlu etkileyecek düzenlemelerin yapılmasının çalışanların etkinliğini ve dolaylı olarak işletmelerin gelirlerini arttıracağı gözönüne alınmalıdır (Afşar, 2014). Özellikle kadınlar için yaşam kalitesi algılarının yukarıda anlatılanlar 1şı̆̆ı̆nda çalışma ve yaşam koşullarının hem nesnel hem öznel değerlendirmelerle şekillendiği tartışılmıştı. Sirgy vd. (2008) yaşam kalitesi algılarının örgütsel aidiyet, iş memnuniyeti ve iş performansını olumlu olarak etkilediğini ifade etmektedir. $\mathrm{Bu}$ nedenle nesnel ve öznel koşulları olumlu etkileyecek düzenlemelerin dolaylı olarak örgütsel aidiyeti, iş memnuniyetini, iş performansını da etkileyebileceğ düşünülmektedir. Nesnel olarak bakıldığında yaşam kalitesinin çalışanlar için belirleyenleri ücretler, (esnek) çalışma saatleri, çalışma koşulları, iş güvenliği olmaktadır (Davis, 1983). Ancak nesnel etkenlerin her çalışan tarafından aynı algılanamayacağı ve bu farklı algıların yaşam kalitesi algısını da şekillendirebileceğini ileri sürülmektedir (Sirgy vd., 2002). Birey ihtiyacı kuramının da önerdiği gibi bireylerin ihtiyaçlarının iyi analiz edilmesi yaşam kalite algılarını arttıracak tedbirleri şekillendirebilir. Örneğin Hakim (2000) düşük seviyeli bir işte çalışan fakat iç ve dış motivasyonları yüksek olan kadınların yüksek yaşam memnuniyetine sahip olduğunu iddia etmiştir. Fahey vd. (2003) kadınlar için iş ve aile rolleri arasındaki dengenin yaşam memnuniyetinin temel belirleyicisi olduğunu ifade etmektedir. Uygun bir iş ve aile rol dengesinin kadınlar için hemen hemen tüm kültürlerde yaşam kalitesi algısının da belirleyicisi olduğu öne sürülmektedir (Wallace ve Lemaire, 2007). Hofstede'in gözlemlerine dayanarak kolektivist özellikler taşıyan Türk toplumunda aile bireylerinin geleneksel bakış açısının dışına çıkarak, günümüz gereklerine göre çocuk yetiştirme ve ailedeki diğer sorumluluklara ortak olması, kadının ev ve iş rolleri arasındaki dengeyi kurmasını sağlayabilir. Avrupa Birliğinin kadın iş hayatına katılımını arttırıcı politikalarının temel vurgusu da bu olmaktadır (EUC, 2017). Kadının iş ve evine ilişkin rollerinin sorumluluğunun sadece kadına yüklenemeyeceğini, bu dengenin kurulması için birtakım kalıcı devlet politikaların uygulanması gerektiği ifade edilmektedir. Wallace vd. (2007) çalışmaları kadının iş ve aile dengesinin kurmasının yaşam memnuniyeti ve dolayısıyla yaşam kalite algısının temel belirleyicisi olduğunu göstermektedir. Kurum yaptığı araştırmada kadınların iş-aile dengesini sağlayabildiği sürece yaşam memnuniyetinin arttığını iddia etmektedir

\section{2. Öneriler}

Her şeyden önce ataerkil ağırlıklı normların egemen olduğu Türk toplumunda kadına olan genel bakış açısı ve sübjektif değerlendirmelerin bir anda değiştirilmesi mümkün gözükmemektedir. Bu konunun geniş kapsamlı bir şekilde yaygın ve örgün eğitimde müfredat konularında işlenmesi, özellikle kırsal kesimde ve büyük şehirlerin varoşlarında yaşayan ailelerin devlet veya STK'lar yardımı ile eğitilmeleri gibi önlemlerin alınması ancak orta ve uzun vadede bir değişiklik beklentisi yaratabilecektir. Herşeyden önce araştırmada da çıkan en önemli bulgu, kadınların algılayacağı yaşam kalitesindeki ciddi bir iyileşmenin duyumsuyacakları baskı ve stresi ciddi ölçüde azaltabileceğinin görülmesidir. Toplumsal refah seviyesinin artması ile yaşam koşullarında yaşanacak göreceli iyileşmenin de bu bağlamda faydalı olabileceği değerlendirilmektedir.

4857 sayılı İş Kanunu işyerinde "eşit davranma ilkesi" başlıklı 5. Maddesi çalışanın ayrıma tabi tutulamayacağı, çalışanlar arasında eşit davranılması gerekliliğini düzenlemektedir. Ancak uygulamada sıkıntıların olduğu ve etkin denetleme yapılamadığından işyerlerinin kendi işine gelecek şekilde kanunu yorumlayıp uyguladığı gözlemlenmektedir. Ayrıca Türkiye'nin işgücü piyasası ve işgücü istatistiklerine göre cinsiyete dayalı mesleki ayrımcılığın mevcut olduğu ve özellikle kadınların bundan dolayı işgücü piyasasında birtakım sorunlarla karşılaştığı öne sürülmektedir (Parlaktuna, 2010: 1223'ten aktaran Alparslan vd., 2015). Öyle görülüyor ki kadınlar daha çok düşük maaş ve tekdüze mesleklerin ağırlıkta olduğu işlerde çalışmaktadırlar (Giddens, 2000:340'tan aktaran Alparslan vd., 2015). Kısa vadede alınabilecek önlemler arasında kadın çalışanların liyakatı ve performansı ölçüsünde erkeklere denk maaş ve yan ödemelerle göreceli yaşam kalitesinin arttırılabileceği değerlendirilmektedir.

Son olarak 6715 sayılı iş kanuni ile yasal hale getirilen uzaktan ve esnek çalışma imkanlarından özellikle kadın çalışanların yararlandırılması yönünde teşviklerin ve bilinçlendirmenin yapılması ve pozitif ayırımcılık kapsamında 6331 sayılı İş Sağlığı ve Güvenliği kanununa dayanılarak, kimi işyerlerinde kreş açma zorunluluğunun (150’den fazla kadın çalışanı olan işyerlerinde) uygulanması ve denetimi ile kısa vadede kadınlar için yaşam kalitesi algısında farkındalık yaratılabilecek önerilerden bazılarını oluşturmaktadir.

\section{Kaynakça}

Afşar, S.T. (2014). Impact of Quality of Work-life on Organizational Commitment, International Journal of Social Sciences, 3(4), 124-152.

Akdogan, A. A., \& Demirtas, O. (2014). Managerial role in strategic supply chain management. Procedia-Social and Behavioral Sciences, 150, 1020-1029.

Akdoğan, A., \& Demirtaş, Ö. (2014). Etik liderlik davranişlarinin etik iklim üzerindeki etkisi: örgütsel politik algilamalarin aracilik rolü. Journal of Economics and Administrative Sciences, 16(1), 103120.

Alparslan, A.M., Bozkurt, Ö.Ç. ve Özgöz, A. (2015). İşletmelerde Cinsiyet Ayrımcılı̆̆ 1 ve Kadın Çalışanların Sorunları, MAKÜ Iktisadi ve Idari Bilimler Fakültesi Dergisi, 2(3), 66-81.

Amato, F. J. (2012). The Relationship of Violence to Gender Role Conflict and Conformity to Masculine Norms in a Forensic Sample, The Journal of Men's Studies, 20(3), 187-208.

Azar, O.H. (2004). What sustains social norms and how they evolve? The case of tipping, Journal of Economic Behavior and Organization 54, 49-64.

Beaglaoich, C., Sarma, K. ve Morrison, T.G. (2013). New directions in gender role conflict research. In Gelfer, 
J. (Ed.), Masculinities in a global era (pp. 17-51). New York: Springer.

Bem, S. L. (1981). Gender schema theory: A cognitive account of sex typing, Psychological Review, 88, 354364.

Bicchieri, C. (2014). Norms, conventions, and the power of expectations. In Cartwright, N. and Montuschi, E. (Eds.), Philosophy of social science: A new introduction (pp. 208-229). Oxford: Oxford University Press.

Blackmore, J. E. O. (2003). Children's beliefs about violating gender norms: Boys shouldn't look like girls, and girls shouldn't act like boys, Sex Roles, 48, 411-419.

Bognar (2005). The Concept of Quality of Life, Social Theory \& Practice, 31(4), 561-580.

Boudet, A.M., Pettesch, P. ve Turk, C., with Thumala, A. (2012). On Norms And Agency. Conversations with Women and Men about Gender Equality in 20 Countries. Washington, DC: World Bank. (http://bit.ly/1jGGobQ, 12 Nisan 2017 tarihinde erişildi).

Bronfenbrenner, U. (2005). Making human beings human: Bioecological perspectives on human development. Thousand Oaks, CA: Sage.

Cialdini, R. B., \& Trost, M. R. (1998). Social influence: Social norms, conformity and compliance.

Costanza, R. vd. (2007). Quality of Life: An Approach Integrating Opportunities, Human Needs, and Subjective Well-Being, Ecological Economics, 61, 267-276.

Coyle, D. (2015). GDP: A Brief but Affectionate HistoryRevised and expanded Edition. Princeton University Press.

Crane, M. ve Markus, H. (1982). Gender identity: Benefits of a self-schema approach, Journal of Personality and Social Psychology, 43, 1195-1197.

Cummins, R.A., Eckersley, R., Pallant, J., Van Vugt, J. ve Misajon, R. (2003). Developing a national ndex of subjective wellbeing: the Australian Unity Wellbeing index, Social Indicators Research 64, 159-190.

Davis, L. E. (1983). Design of new organizations.In H.Kolodny \& H.V.Beinum (Eds.), The quality of working life and the 1980s. New York: Praeger Publishers.

Demirtaş, Ö. (2014). İşyerlerinde olumsuz durumları ifşa etmenin etik iklim üzerindeki etkisi: Yıldırma algısının moderatör rolü. Istanbul University Journal of the School of Business Administration, 43(1).

Diener, E. (2006). Guidelines for national indicators of subjective well-being and ill-being, Journal of Happiness Studies, 7(4), 397-404.

Diener, E., \& Suh, E. M. (2000). Measuring subjective wellbeing to compare the quality of life of cultures. Culture and subjective well-being, 3-12.

Doyal, L. ve Gough, I. (1991). A theory of human need. London: Macmillan.

Dökmen, Z. Y. (2004). Toplumsal cinsiyet, sosyal psikolojik açıklamalar. Sistem yayıncılık.

Dudte, K. (2008). Social Influence and Gender Norms. Ohio State University, Unpublished Doctoral Thesis, 2008.

Eagly, A. H., Beall, A. ve Sternberg, R. S. (Eds.). (2004). The psychology of gender (2nd ed.). New York: Guilford Press.
Efthim, P. W., Kenny, M. E. ve Mahalık J. R. (2001). Gender Role Stres in Relation to Shame, Guilt, and Externalization, Journal of Counselling \& Development, 79, 430-438.

EUC (2017). Report on Equality between Women and Men in the EU. European Commission Report. Belgium.

Fahey, T., Nolan, B. ve Whelan, C. (2003). Monitoring quality of life in Europe, European Foundation for the Improvement of Living and Working Conditions, Office for Official Publications of the European Commission, Luxembourg, 2003.

Gillespie, B.L. ve Eisler, R.M. (1992). Development of the Feminine Gender Role Stress Scale: A cognitivebehavioral measure of stress, appraisal, and coping for women, Behavior Modification, 16, 426-438.

Greenhaus, J. H. ve Beutell, N. J. (1985). Sources of conflict between work and family roles, Academy of Management Review, 10(1), 76-88.

Haas, B.K. (1999). A multidisciplinary concept analysis of quality of life, Western Journal of Nursing Research, 21, 728-742.

Hagerty, M. R., Cummins, R., Ferriss, A. L., Land, K., Michalos, A. C., Peterson, M., ... \& Vogel, J. (2001). Quality of life indexes for national policy: Review and agenda for research. Bulletin of Sociological Methodology/Bulletin de Méthodologie Sociologique, 71(1), 58-78.

Hakim, C. (2000). Work-Lifestyle Choices in the 21st Century: Preference Theory. Oxford: Oxford University Press.

Hayes, J. A., \& Mahalik, J. R. (2000). Gender role conflict and psychological distress in male counseling center clients. Psychology of Men \& Masculinity, 1(2), 116.

Hofstede, G. (1984). Culture's Consequences: International Differences in Work-related Values (abridged ed.). Beverly Hills, CA: Sage Pub.

Kagawa-Singer, M., Padilla, G. V. ve Ashing-Giwa, K. (2010). Health-related quality of life and culture, Seminars in Oncology Nursing, 26, 59-67.

Kahn, R.L. ve Quinn, R.P. (1970). Role stress: A framework for analysis. In McLean, A. (Ed), Occupational mental health. New York NY:Rand-McNally.

Levant, R. F. vd. (2007). Initial validation of the Male Role Norms Inventory-Revised (MRNI-R), The Journal of Men's Studies, 15(1), 83-100.

Liu, W. M., Rochlen, A. ve Mohr, J. J. (2005). Real and ideal gender-role conflict: Exploring psychological distress among men, Psychology of Men \& Masculinity, 6(2), 137-148.

Lytton, H. ve Romney, D. M. (1991). Parents' differential socialization of boys and girls: A meta-analysis, Psychological Bulletin, 109, 267-296.

Mahalik, J. R. vd. (2005). Development of the conformity to Feminine Norms Inventory, Sex Roles, 52, 417-435.

O’Neil, J. M. ve Denke, R. (2016). An empirical review of gender role conflict research: New conceptual models and research paradigms. In Wong, Y. J., Wester, S. R., Wong, Y. J., and Wester, S. R. (Eds.), APA handbook of men and masculinities (pp. 51-79). Washington, DC, US: American Psychological Association.

O’Neil, J.M. (2008). Summarizing 25 years of research on men's gender role conflict using the gender role conflict scale: New research paradigms and clinical 
implications, The Counseling Psychologist, 36(3), 358-445.

Oishi, S., \& Diener, E. (2001). Re-examining the general positivity model of subjective well-being: The discrepancy between specific and global domain satisfaction. Journal of Personality, 69(4), 641-666.

Paluck, E.L. ve Ball, L. (2010). Social Norms Marketing Aimed at Gender Based Violence: A Literature Review and Critical Assessment. NY: International Rescue Committee.

Pereira, R. G., Sirker, J., Caux, J. S., Hagemans, R., Maillet, J. M., White, S. R., \& Affleck, I. (2006). Dynamical spin structure factor for the anisotropic spin-1/2 Heisenberg chain. Physical review letters, 96(25), 257202.

Pool, G.J, Schwegler, A.F, Theodore B.R ve Fuchs P.N (2007). Role of gender norms and group identification on hypothetical and experimental pain tolerance, Pain, 129, 122-129.

Ratzlaff, C., Matsumoto, D., Kouznetsova, N., Raroque, ve Ray, R. (2000). Individual psychological culture and subjective well-being. In Diener, E. and Suh, E. M. (Eds.), Culture and subjective well-being (pp. 37-60). Boston, MA: Massachusetts Institute of Technology.

Repetti, R. L. (1987). Linkages between work and family roles, Applied Social Psychology Annual, 7, 98-127.

Richmond, K., Levant, R., Smalley, B. ve Cook, S. (2015). The Femininity Ideology Scale (FIS): dimensions and its relationship to anxiety and feminine gender role stress, Women \& Health, 55(3), 263-279.

Ridgeway, C.L. (1997). Interaction and the conservation $f$ gender inequality: considering employment, American Sociological Review, 62, 218-35.

Rothstein, B. ve Tannenberg, M. (2015). The Quality of Government and Development Policy, The Quality of Government Institute Report, 2015. (http://qog.pol.gu.se/digitalAssets/1549/1549815_thequality-of-government-and-development-policy.pdf, 15 Mayıs 2017 tarihinde erişildi).
Ryan, R. M., \& Deci, E. L. (2000). Intrinsic and extrinsic motivations: Classic definitions and new directions. Contemporary educational psychology, 25(1), 54-67.

Schalock, R. L. ve Keith, K.D. (Eds.) (2016). Cross-Cultural Quality of Life: Enhancing the Lives of People with Intellectual Disability (2nd Ed). American Assoc. on Intellectual and Developmental Disabilities.

Schwarz, N. ve Strack, F. (1999). Reports of subjective wellbeing: judgmental processes and their methodological implications. In Kahneman, D., Diener, E., and Schwarz, N. (Eds.), Well-Being: The Foundations of Hedonic Psychology (pp. 61-84). Russell Sage Foundation, New York.

Sirgy, M.J. (2002). The Psychology of Quality of Life. Dordecht, The Netherlands: Kluwer Academic Publishers.

Skevington, S.M.,MacArthur, P. ve Somerset, M.(1997). Developing items for the health in Britain, British Journal of Health Psychology, 2, 55-72.

Stillson, R. W., O'Neil, J. M. ve Owen, S. V. (1991). Predictors of adult men's gender-role conflict: Race, class, unemployment, age, instrumentalityexpressiveness, and personal strain, Journal of Counseling Psychology, 38(4), 458-464.

Sumner, L.W. (1996). Welfare, Happiness, and Ethics. Oxford: Clarendon Press.

Wallace, J. E., \& Lemaire, J. (2007). On physician well being-you'll get by with a little help from your friends. Social science \& medicine,64(12), 25652577.

Ware Jr, J. E., \& Sherbourne, C. D. (1992). The MOS 36item short-form health survey (SF-36): I. Conceptual framework and item selection. Medical care, 473-483.

West, C. ve Fenstermaker, S. (1995). Doing difference, Gender \& Society, 9(1), 8-37.

Zapf, W. (2000). Social Reporting in the 1970s and 1990s, Social Indicators Research, 51, 1-15. 
